ISSN 1676-3742

\title{
Corporeidade na Gaudium et Spes
}

\author{
Corporeity in Gaudium et Spes
}

Jonathan Bahia Vieira

\begin{abstract}
Resumo
Viver é estabelecer relações, relações no corpo e através dele. Somos uma religião do corpo. Revisitar a Constituição Pastoral Gaudium et Spes para este tempo, analisando sua antropologia cristológica extremamente rica para pensar a questão da corporeidade, expressa na unidade e integridade do homem, corpo e alma, criado à imagem de Deus, e visto em sua mais elevada expressão e paradigma: O Cristo encarnado, verdadeiro homem, onde se esclarece o mistério do ser humano.
\end{abstract}

Palavras-Chave: Gaudium et Spes. Corpo. Corporeidade. Ser humano.

\begin{abstract}
To live is to establish relationships, relationships in the body and through it. We are a body of religion. Revisit the Pastoral Constitution Gaudium et Spes for this time, analyzing its extremely rich Christological anthropology to think the issue of corporeity, expressed in the unity and integrity of man, body and soul, created in God's image, and seen in its highest expression and paradigm: the incarnate Christ, true man, where he explains the mystery of the human being.
\end{abstract}

Keywords: Gaudium et Spes. Body. Corporeity. Human being. 


\section{Introdução}

A Constituição Pastoral Gaudium et Spes ${ }^{1}$, documento de suma importância e destaque do Concílio Vaticano II, de maneira corajosa e firme, ainda no século XX, mas com olhar à frente, propôs-se falar sobre o homem a partir de sua concretude. É central o lugar do homem no documento, uma "virada humanista". Analisar a temática da corporeidade ${ }^{2}$ é confrontar-se com a dificuldade de lidar com esta dimensão fundamental e constitutiva do ser humano. Dificuldade, porque a igreja chega até o século XXI, tentando deixar para trás uma suspeita em relação ao corpo que terminou por comprometer uma concepção de ser humano que alija aspectos essenciais da vida humana.

Pretende-se perceber o momento histórico importante onde a Constituição Pastoral surge, momento que traz inúmeros desafios sociais e éticos e que enfrenta um esvaziamento do teológico como via de verdade. A modernidade opera uma virada humanista e a Igreja a enfrenta quando assume uma opção antropológica cristológica para tornar a falar ao homem contemporâneo ao Concílio e mesmo o homem atual.

Daí, analisar na primeira parte da Gaudium et Spes, de cunho mais doutrinal, sua antropologia cristológica extremamente rica para pensar a questão da corporeidade, expressa na unidade e integridade do homem, corpo e alma, aspectos constitutivos do ser humano, criado à imagem de Deus, marca de sua dignidade e alvo da mais elevada expressão e paradigma: $\mathrm{O}$ Cristo encarnado, verdadeiro homem, onde se esclarece o mistério do ser humano, como fundamento válido a refletir a ação humana e a espiritualidade do homem deste tempo.

\section{A Gaudium et Spes e a condição do homem no mundo}

Vinte anos passados do término da Segunda Guerra Mundial, o mundo ainda respirava seus horrores, como o insano genocídio de judeus pelo regime nazista, as bombas nucleares sobre as cidades japonesas de Hiroshima e Nagasaki, a tensão sempre crescente do conflito nuclear que poderia ser deflagrado

\footnotetext{
${ }^{1}$ Será usada a abreviatura comumente aceita: GS.

${ }^{2}$ Neste trabalho, como já indicado em GESCHÉ, A. “A invenção cristã do corpo”. In: GESCHÉ, A.; SCOLAS, P. (orgs.). O corpo, caminho de Deus. São Paulo: Loyola, 2009, p. 38, nota 5, tomar-se-á os termos como: corpo, corporeidade, corporalidade, como sinônimos entre si já que para a abordagem da pesquisa, a distinção entre eles se torna insignificante.
} 
pelas superpotências Norte-Americana e Russa, envolvidas em um jogo de espionagem e contraespionagem conhecido como Guerra Fria.

É também tempo marcado pelo exponencial desenvolvimento e crescimento tecnológico e das telecomunicações. Momento de seríssimas crises nas estruturas sociais. O fenômeno da urbanização acelerada afeta as cidades que veem seus problemas crescerem na mesma proporção. Abismos sociais tornam-se mais graves e intransponíveis, pobreza e miséria crescem junto com o acúmulo de riqueza nas mãos de poucos. Violência e conflitos locais ganham forte repercussão.

Revoluções sociais ganham corpo; talvez a mais expressiva seja a questão da igualdade e dignidade da mulher; a temática é trazida a lume nos principais espaços de discussão social. Há também uma crescente mudança de papéis e a configuração da família vai sofrendo tais abalos.

A Constituição Pastoral Gaudium et Spes é o maior documento do Concílio Vaticano II e o último a ser votado, no último dia do Concílio, em sua última sessão geral ${ }^{3}$. Consta de 93 números; é a única constituição pastoral, uma novidade até então. Foi esta intenção do Papa João XXIII. A igreja deveria realizar um concílio pastoral, abrir-se em um caminho de diálogo com o mundo, olhando com muita seriedade para os problemas da época. ${ }^{4}$

Traz em si um proêmio de grande beleza que já aponta a intenção de não falar somente ao coração do cristão católico. Um documento universal, que se põe em diálogo com todas as gentes: cristãos e não cristãos, religiosos e arreligiosos. A Igreja, inserida no mundo, não em oposição a ele, não em fuga dele, mas participante de todas as questões, demonstra seu real interesse no homem e naquilo que é comum ao humano, por obediência e amor a Cristo.

As alegrias e as esperanças, as tristezas e as angústias dos homens de hoje, sobretudo dos pobres e de todos aqueles que sofrem, são também as alegrias e as esperanças, as tristezas e as angústias dos discípulos de Cristo; e não há realidade alguma verdadeiramente humana que não encontre eco no seu coração. ${ }^{5}$

${ }^{3}$ LOPES, G. Gaudium et Spes: texto e comentário. São Paulo: Paulinas, 2011, p. 9.

${ }^{4}$ LOPES, G. Gaudium et Spes: texto e comentário, p. 44, nota 1: 'É chamada 'Pastoral' porque, apoiando-se em princípios doutrinais, pretende expor as relações da Igreja com o mundo e os homens de hoje. Assim, nem à primeira parte falta a intenção pastoral, nem à segunda a doutrinal. ${ }^{5}$ GS 1 . 
Em esforço sincero de dialogar com a humanidade, em sua introdução a Constituição analisa e ilumina a condição do ser humano no mundo de sua época. O ser humano, a despeito de tudo que tenha conquistado e realizado, e todo desenvolvimento que as racionalidades suscitaram, está imerso em caudalosa angústia trazida pelo crescimento da maldade, do egoísmo, da miséria. De maneira firme, discernindo seu tempo, ainda no século XX, mas com olhar à frente, propôs-se falar sobre o homem a partir de sua concretude. É central o lugar do homem no documento, uma "virada humanista". Não um homem partido, divorciado e em litígio com suas dimensões, mas um ser integral e integrado. Em sua primeira parte, de cunho mais doutrinal, o documento nos oferece uma antropologia teológica, ou pode-se dizer, uma antropologia cristológica extremamente rica para pensar não somente os aspectos constitutivos do ser humano, mas sua dignidade como ser criado, o resultado destas compreensões para a vida. É afirmado o grande acerto em sua corajosa disposição de falar a partir de uma antropologia cristológica.

Alfonso Garcia Rubio afirma que, apesar dos avanços sensíveis no pensar teológico desde o esforço do Vaticano II, em propor uma teologia em diálogo com o mundo da cultura moderna/pós-moderna, muito ainda há por fazer. No que diz respeito à visão do ser humano, diante do avanço e descoberta das ciências, a Igreja foi muito criticada. Esta, ressentida, se apegou a concepções antigas, do homem e do mundo ampliando tal enfrentamento e ruptura com a modernidade. ${ }^{6}$

\section{Corpo e Modernidade - Virada Antropológica}

Joseph Famereé, no capítulo Corpo, caminho de Deus - A problemática $^{7}$, refletindo sobre a questão antropológica na modernidade, seguindo os passos do filósofo Yves Ledure em seu texto cujo título é: Si Dieu s'efface. La corporéité comme lieu d'une affirmation de Dieu. [Se Deus desaparece. A corporeidade como lugar de afirmação de Deus], afirma que a modernidade marca o fim da metafísica na existência humana. As realidades que ordenam o mundo não são mais oriundas da revelação e da transcendência. Uma nova perspectiva de verdade surge e brota do próprio homem, de sua racionalidade

${ }^{6}$ RUBIO, A.G. (org.). O humano integrado. Abordagens de antropologia teológica. Petrópolis: Vozes, 2007, p. 268.

${ }^{7}$ FAMERÉE, Joseph. “O corpo, caminho de Deus. A problemática”. In: GESCHÉ, A.; SCOLAS, P. (orgs.). O corpo, caminho de Deus. São Paulo: Loyola, 2009, pp. 13-34. 
e capacidade. A percepção de eternidade se desfaz. Na modernidade tudo flui e se torna fragmentado. O homem moderno nasce sem um Criador, cresce sem uma ordenação instituída por Deus e morre sem perspectiva da eternidade. O desaparecimento de Deus é consequência da superação da metafísica, compreendida como fase pré-científica, mitológica e fantasiosa.

Segundo Famereé, o cristianismo desde o início e durante bom tempo se "expressou no discurso da metafísica platônica". O mundo visível e invisível em uma dualidade vertical. Dualidade que instala-se no próprio homem como realidade constituída de corpo-alma. O problema é que tal dualismo é somente uma máscara para "um monismo intransigente": o corpo sendo negado, tornando-se não valor, e uma imposição da alma, "a esfera autônoma do suprassensível."

Importante dizer então: "É precisamente isso que a modernidade recusa. Sem criticar o não corpóreo enquanto tal, a modernidade põe o corpo como única realidade, única instância do homem". A corporeidade define e limita o espaço da vida, pois esta somente se dá no corpo. Sendo o homem, seu corpo, nada do que é do corpo é estranho ao humano, e nada do que é humano pode ser vivido fora do corpo. ${ }^{8}$

A Igreja percorrendo ainda os desafios e entraves que a modernidade impõe à fé cristã, em síntese, de maneira corajosa e vibrante percebe que possui todos os elementos e possibilidades para ainda falar a este homem. Pois Deus é vida e a vida que outorga somente pode ser vivida na realidade histórica e concreta. "Deus só pode nascer no homem nessa corporeidade, tornando-se relação, tomando corpo no livre desejo do homem que crê, no desejo de um corpo necessariamente sexuado, masculino ou feminino com todos os equívocos desse desejo de Deus".

Se o corpo, como define Erich Fuchs, “...é a própria pessoa do ser humano marcado pelo limite de sua condição de criatura e chamado ao encontro do outro". ${ }^{10}$ É exatamente pela maravilhosa novidade da afirmação de um Deus que busca o encontro e para tal assume a carne que se dá toda possibilidade de relação. Uma perspectiva antropológica que, ao invés de gerar o afastamento da Igreja, serve de motriz evangelizadora, já que o evangelho sempre se ocupou

${ }^{8}$ FAMERÉE, Joseph. $O$ corpo, caminho de Deus. A problemática, p. 21.

${ }^{9}$ FAMERÉE, Joseph. O corpo, caminho de Deus. A problemática, p. 24.

${ }^{10}$ FUCHS, Eric (?), p. 218. Apud: REIJNEN, A. M. "O corpo, canteiro de obras da redenção". In: GESCHÉ, A.; SCOLAS, P (orgs.). O corpo, caminho de Deus. São Paulo: Loyola, 2009, pp. 203-220. 
disso: a necessidade de comunicar-se aos homens indo-lhes ao encontro. A antropologia teológica desponta com maior intensidade neste momento.

E o que a Fé Cristã tem a falar para este homem?

\section{Corporeidade na Gaudium et Spes: Corpo para falar do humano, corpo para falar de Deus}

A virada antropológica operada pela modernidade ${ }^{11}$ não foi bem entendida de início pela Igreja, que viu-se ameaçada e pesadamente criticada. Segundo Junges $^{12}$, no surgimento do iluminismo, o cristianismo na vertente católica teve dificuldades de compreendê-lo, entra em combate com o humanismo moderno, condenando conquistas hoje plenamente aceitas.

O Concílio Vaticano II marca uma virada na disposição da Igreja, uma reformulação de sua linguagem, em uma nova disposição de fazer-se entender em seu humanismo. ${ }^{13}$ Diz que o Concílio abriu-se ao mundo moderno. Para o Papa João XXIII, isto significava uma abertura ao mundo moderno na perspectiva de participar de um diálogo que exigia sua presença, pois o mundo lançava as perguntas e esperava respostas. Respostas estas que precisavam tornar-se acessíveis ao entendimento diante das aspirações do homem moderno.

O Concílio Vaticano II quis ser pastoral no momento em que aceitou a tese oposta a uma das afirmações do Syllabus de Pio IX. Condenara-se a seguinte proposição: "O Romano Pontífice pode e deve reconciliar-se e fazer amizade com o progresso, o liberalismo e a civilização moderna". (DS 2980). Não se tratava da Igreja reconciliar-se ou fazer amizade de uma maneira subserviente, capitulante, abrindo mão de sua originalidade e identidade, mas de abertura. ${ }^{14}$

A Constituição Pastoral Gaudium et Spes é entendida como o documento que melhor conseguiu expressar esta abertura, esta reconciliação. A Igreja

${ }^{11}$ LIBANIO, J.B. Concílio Vaticano II: em busca de uma primeira compreensão. São Paulo: Edições Loyola, 2005, p.10.

${ }^{12}$ JUNGES, J. R. Bioética. Hermenêutica e casuística. São Paulo: Loyola, 2006, p. 126.

${ }^{13}$ JUNGES, J. R. Bioética. Hermenêutica e casuística, p. 126: “em toda história o cristianismo sempre se apresentou como humanismo. O fundamento desta vocação está em duas afirmações fundamentais do dogma cristão: A encarnação do Verbo de Deus e a ressurreição do corpo. O Filho de Deus assume a carne, o corpo, e o corpo não é deixado esquecido, mas redimido participa da realidade salvífica".

${ }^{14}$ LIBANIO, J.B. Concílio Vaticano II: em busca de uma primeira compreensão, p. 68. 
pode dialogar com todas as gentes em todos os lugares porque a base está na antropologia apresentada no documento, especialmente em toda primeira parte. Esta é a riqueza e toda novidade da GS, uma antropologia cristológica. Pois aponta para o homem, "em sua unidade e integridade: corpo e alma, coração e consciência, inteligência e vontade," 15 mas este somente encontra sua determinação e plenificação em Cristo Jesus. ${ }^{16}$

A exposição preliminar descrita nos números de 4 a 10 falam da condição humana. O homem está em um período bem controverso de mudanças. Mudanças sociais e políticas. Mudanças morais e éticas; época também marcada por grandes desequilíbrios, desequilíbrios sociais, crescentes níveis de pobreza e miséria, e acúmulo de riquezas por pequena parcela da população mundial, violência e toda sorte de questões oriundas disto. Desequilíbrios ecológicos, que também é um legado do desenvolvimento irrefletido, a exploração desenfreada e predatória dos recursos naturais. O documento está dividido em duas grandes partes; a primeira vai dos números 11 a 45: A Igreja e a Vocação Humana. Está dedicada a mostrar o interesse da Igreja nos temas atuais e toma por base um ponto de partida irrenunciável: A Dignidade da Pessoa Humana, dignidade alicerçada na compreensão da Sagrada Escritura quando ensina que "o homem foi criado à imagem de Deus".

A Sagrada Escritura ensina que o homem foi criado «à imagem de Deus», capaz de conhecer e amar o seu Criador, e por este constituído senhor de todas as criaturas terrenas (1), para as dominar e delas se servir, dando glória a Deus (2). «Que é, pois, o homem, para que dele te lembres? ou o filho do homem, para que te preocupes com ele? Fizeste dele pouco menos que um anjo, coroando-o de glória e de esplendor. Estabeleceste-o sobre a obra de tuas mãos, tudo puseste sob os seus pés» (Salmo 8, 5-7).

Deus, porém, não criou o homem sozinho: desde o princípio criou-os «varão e mulher» (Gén. 1,27); e a sua união constitui a primeira forma de comunhão entre pessoas. Pois o homem, por sua própria natureza, é um ser social, que não pode viver nem desenvolver as suas qualidades sem entrar em relação com os outros. ${ }^{17}$

${ }^{15}$ GS 3.

${ }^{16}$ Cf. Tese de COSTA, P. C. “A determinação cristológica do ser humano”. Atualidade Teológica 39 (2011), pp. 503-511.

${ }^{17}$ GS 12 . 
O trecho citado aponta três aspectos desta imagem de Deus no ser humano, segundo Junges; "a capacidade de conhecer e amar a Deus, de ser senhor sobre todas as coisas e de viver em comunhão com os outros". Neste entendimento, esta imagem não é somente um dado, mas aponta para o projeto de Deus para a vida humana, um jeito de viver. A imagem de Deus refletida no homem configura-se também como dinamismo que abre o ser humano para três relações: com Deus, com o outro e com o mundo. "Nessas relações efetiva-se sua vocação: entrar em comunhão com Deus, com o outro e com mundo. A dignidade humana consiste nesta efetivação". ${ }^{18}$

A pessoa humana em sua unidade e integralidade é a base de toda exposição deste documento. A imagem de Deus realiza-se em uma unidade, "ser uno", numa estrutura corpóreo-espiritual "corpo e alma". Dimensões que precisam ser trazidas em completa harmonização e consciência. Não deve desprezar a vida corporal, ao contrário, deve dignificá-la, pois seu corpo é bom, dádiva maravilhosa de Deus, mas o homem não se encerra no corpo somente. Percebe-se superior às coisas materiais. "Ao reconhecer em si uma alma espiritual e imortal, não se ilude com uma enganosa criação imaginativa, mero resultado de condições físicas e sociais; atinge, pelo contrário, a verdade profunda das coisas". ${ }^{1}$ "Sua condição corporal e vida interior são as mediações para a realização da vocação e a base para a efetivação da dignidade". ${ }^{20}$ Como bem afirma Helmut: "Somos parte da criação, sem corpo não existimos no espaço e no tempo, teologia da criação é teologia corporal". ${ }^{21}$

Contudo, longe de idealizar o homem e sua saga histórica, a Igreja também lhe aponta os motivos de desagregação de si mesmo, do rompimento brusco de suas relações e uma determinada opção pela violência, poder e enfrentamentos. O pecado, como opção de autonomia estéril do homem em relação a Deus, acaba por encarcerá-lo em processo de não-realização de si mesmo, de desumanização até a morte. ${ }^{22}$ "O homem encontra-se, pois, dividido em si mesmo. E, assim, toda a vida humana, quer singular, quer coletiva, apresenta-se como uma luta dramática entre o bem e o mal, entre a luz e as trevas". ${ }^{23}$

${ }^{18}$ JUNGES, J. R. Bioética. Hermenêutica e casuística, p. 127.

${ }^{19} \mathrm{GS} 14$

${ }^{20}$ JUNGES, J. R. Bioética. Hermenêutica e casuística, p. 127.

${ }^{21}$ RENDERS, H. A. "Estudos de gênero e método teológico: corporeidade e androcentrismo como temas permanentes do quadrilátero wesleyano brasileiro". Revista Estudos de Religião 39 (2010), p. 103. Disponível em: <https://www.metodista.br/revistas/revistas-ims/index.php/ER/ article/view/2076/2343>. Acesso em 15 de Maio de 2015.

${ }^{22} \mathrm{Cf}$. GS 13.

${ }^{23} \mathrm{GS} 13$ 
O ser humano, criado para encontrar sua plena realização na acolhida amorosa do Criador, experimenta as "revoltas do corpo", isto porque é pelo seu corpo que vive e nele experimenta as dores e angústias históricas consequência do seu descaminho. Apesar disto, deve antes considerar "o seu corpo como bom e digno de respeito, pois foi criado por Deus e há de ressuscitar no último dia."24

Por isso, a contribuição mais importante e original do Concílio para a antropologia teológica é a revelação do Cristo. Nele se esclarece o mistério do homem.

\begin{abstract}
"Na realidade, só no mistério do Verbo encarnado se esclarece verdadeiramente o mistério do homem. Adão, o primeiro homem, era efetivamente figura daquele futuro, isto é, de Cristo Senhor. Cristo, novo Adão, na própria revelação do mistério do Pai e do seu amor, revela o homem a si mesmo e descobre-lhe a sua vocação sublime. Não é por isso de admirar que as verdades acima ditas tenham nele a sua fonte e nele atinjam a plenitude". Imagem de Deus invisível» (Col. 1,15) (21), Ele é o homem perfeito, que restitui aos filhos de Adão semelhança divina, deformada desde o primeiro pecado. Já que, n'Ele, a natureza humana foi assumida, e não destruída (22), por isso mesmo também em nós foi ela elevada a sublime dignidade. ${ }^{25}$

Ladaria explica:

Jesus é o revelador do Pai e de seu amor; justamente por isso se manifesta a si mesmo como Filho. Mas nessa revelação, diz-nos o Concílio, mostra também o que somos, a dignidade de nossa vocação; neste contexto, esta última não pode ser senão a filiação divina, à imagem da filiação de Jesus. ${ }^{26}$
\end{abstract}

Nos quatro capítulos da primeira parte, os números finais apontam sempre a presença do Cristo na trajetória humana, não como alguém que vem de fora e completamente deslocado do sentido de existência humana, mas como Verbo que se fez carne, Cristo, homem novo. (números 22, 32, 39, 45). Nestes números pode-se identificar traços fundamentais de uma Cristologia Conciliar: $\mathrm{O}$ mistério do homem à luz de Cristo. $\mathrm{O}$ homem sem Deus não tem sentido. Uma linguagem antropológica cristológica, isto é, uma antropologia que tem em

${ }^{24}$ Cf. GS 14.

${ }^{25}$ GS 22 .

${ }^{26}$ LADARIA, L. F. Introdução à antropologia teológica. São Paulo: Loyola, 2002, p. 27. 
seu centro e seu cume na imagem de Cristo. É esta antropologia que vai permitir à Igreja dialogar com qualquer pessoa, não importa sua condição e sua fé. Cristo é apresentado como ápice da experiência e condição humana.

E nesta disposição, a corporeidade assume lugar privilegiado para se falar do humano, pois, segundo Moser, é no corpo que a identidade humana se dá, se concretiza, se torna histórica, faz-se cultura. ${ }^{27}$ Corpo que morre, mas traz em si o anelo da redenção e da eternização, via alcançada somente em Cristo, apresentado como ser humano em sua plenitude e único que pode conduzi-lo a tal.

É pelo corpo que a pessoa humana se expressa, se faz presente e se comunica aos outros seres humanos; é pelo corpo igualmente que a pessoa humana intervém no mundo das coisas transformando-o e criando cultura. ${ }^{28}$

Por isso, Garcia Rubio ainda afirma: o corpo humano não é mero objeto, não está reduzido aos limites biológicos, mas sendo corpo-alma, é onde o homem se autopercebe como corporeidade, que somente cumprirá sua destinação orientado ao encontro das pessoas, e ao relacionamento com o mundo (criação).$^{29} \mathrm{E}$ a relação com Deus, o que será dito no próximo tópico.

O que ocorre hoje, ao se falar de "corporeidade" não é certamente uma volta atrás no espaço e no tempo, mas, antes, uma compreensão mais dialética de toda a realidade, e, portanto, também do corpo. Nesta compreensão, ao mesmo tempo em que o corpo estabelece limites, é por meio dele que, direta ou indiretamente, se estabelecem todas as relações: cósmicas, familiares, políticas, sociais. Com isto se reconhece que não apenas nascemos da conjugação de dois corpos, como criamos consciência de quem somos e de quem devemos ser através do confronto com os corpos dos outros e das demais realidades. A consciência de ser e de existir pressupõe a consciência de ser-com-os-outros e de co-existir. ${ }^{30}$

Falar sobre o corpo não é apenas tratar de sua carne, da dimensão biológica, mas de pensá-lo como símbolo e expressão cultural existente senão também

\footnotetext{
${ }^{27}$ MOSER, A. "Corpo e sexualidade: do biológico ao virtual”. Disponível em: $<$ http://www. antoniomoser.com/site/index.php?option=com_content\&view=article \&id=187:o-corpo-e-sexualidade-do-biologico-ao-virtual\&catid=34:artigos\&Itemid=41>. Acesso em 18 de Maio de 2015.

${ }^{28}$ RUBIO, A. G. Unidade na pluralidade. 3. ed. São Paulo: Paulus, 2001, p. 346.

${ }^{29}$ RUBIO, A. G. Unidade na pluralidade, p. 349.

${ }^{30}$ MOSER, A. "Corpo e sexualidade: do biológico ao virtual".
} 
incorreremos no erro que ora salientamos, reduzir o ser humano a uma só de suas dimensões, absolutizada, na percepção que dela fazemos. Trata-se da unidade vivida na dualidade de aspectos ou dimensões básicas, pois a pessoa percebe-se corpórea, mas não redutível ao que o corpo é somente. Nesta autopercepção existe o grande risco de, na infiltração do dualismo, incorrer no erro de desvalorização do corpo, e das dimensões da corporeidade. ${ }^{31}$

\section{Corpo, lugar de Deus, lugar para Deus}

Na reflexão teológica atual, a questão da corporeidade se insere como bastante pertinente. Um dos teólogos que preocupa-se em analisar e apontar considerações sobre tais questões é Adolphe Gesché. ${ }^{32}$ Não obstante todo patrimônio que nos legou, como último ato de reflexão teológica, fomenta uma discussão cuja perspectiva visa a contribuir para a elaboração de uma proposta cristã para este tempo. Mesmo entrando num período de debilidade física, em seu último estágio de vida, dá-nos contribuição importante. Em seu último pronunciamento em público, um mês antes de falecer, Gesché coloca a questão da necessidade de uma redescoberta do corpo como lugar teológico, ao mesmo tempo que vê a reflexão antropológica interessar-se por esta dimensão humana, como fundamental a pensar o homem e suas relações no mundo. O corpo apresenta-se como uma interface de redescoberta do homem e de aproximação com o outro, e sobretudo de vivências relacionais em Deus. Pois é lugar onde Deus encontra o homem, mas também lugar onde o homem encontra Deus.

Como chegar a Deus pelo corpo? Desenvolvemos um sem-número de provas de Deus ou de acesso a Deus, por meio de ideias, conceitos, interioridade, racionalidade, etc. O corpo foi quase esquecido nesses caminhos, mas na verdade é de uma importância extraordinária na Escritura e no pensamento (na fenomenologia, por exemplo) de hoje. Diferente do animal que é carne, o homem é corpo, o que é bem diferente. Não é pelo nosso corpo (implicando sempre a carne) que vivemos e mantemos harmonia com as coisas e com os outros? Nosso corpo de prazer, como nosso corpo de sofrimento. Não poderíamos esclarecer toda essa questão em uma perspectiva teológica:

\footnotetext{
${ }^{31}$ Cf. RUBIO, A.G. Elementos de antropologia teológica. Salvação cristã: salvos de quê e para quê?. $4^{\mathrm{a}}$ ed. Petrópolis: Vozes, 2007.

32 1928-2003, Padre da diocese de Malines e Bruxelas, mestre e doutor em Teologia. Foi membro da Academia Real da Bélgica e professor emérito da faculdade de Teologia da Univerdiade Católica de Louvain, em Louvain-la-Neuve.
} 
como nos relacionamos com Deus pelo nosso corpo? O corpo não seria o lugar de visita de Deus e, principalmente, o lugar em que pudéssemos fazer vibrar em nós o encontro com Deus? ${ }^{33}$

Gesché inicia sua fala chamando a atenção para a grande e maravilhosíssima novidade declarada por São João: "O logos se fez carne e habitou entre nós".

Jesus é a Palavra de Deus que se fez carne, João não diz, ao menos não afirma formalmente, que a Palavra se fez homem, nem mesmo que ele assumiu um corpo; o que ele afirma cruamente é que ele assumiu a carne (sarx egeneto, caro factum est, se fez carne). ${ }^{34}$

Um Deus capaz do ser humano ${ }^{35}$, sim, pois não foi do alto de uma transcendência incandescente que veio ao homem, mas em sua própria humanidade, que é nossa ${ }^{36}$ Deus vem a nós, pela encarnação, assumindo nossa carne, e nos convida a ir até Ele, em sua carne, assumindo a humanidade que Ele nos outorgou. É o caminho da verdadeira humanização que nos eleva a Deus. Algo inédito ao entendimento visto na percepção da religiosidade humana que compreende enganosamente que para chegar-se a Deus o ser humano precisa rejeitar a si mesmo.

Refletindo sobre a questão da encarnação, a Prof ${ }^{a}$. Olga Consuelo foi buscar na tradição cristã da Kénose tal entendimento (Fp 2:5-11; II Co 8:9). $\mathrm{O}$ ato da encarnação de Cristo, onde Deus faz-se carne, humilha-se no sentido de limitar-se já é visto em todo drama da relação de alteridade de Deus com aquilo que foi criado. Na criação Deus permite que existam seres distintos de Si. Para coexistir com mundo finito fez-se necessário que Deus se autolimitasse, e este é compreendido como primeiro ato da graça. A criação é o primeiro ato da graça de Deus. Primeiro ato de doação. "Sólo dios puede limitar a Dios". ${ }^{37}$ Conforme a citação que faz de Moltmann, é ainda necessário

${ }^{33}$ SCOLAS, P. "O corpo, caminho de Deus, ou a invenção cristã do corpo". In: GESCHÉ, A.; SCOLAS, P (orgs.). O corpo, caminho de Deus. São Paulo: Loyola, 2009, p. 9.

${ }^{34}$ GESCHÉ, A. "A invenção cristã do corpo". In: GESCHÉ, A.; SCOLAS, P (orgs.). O corpo, caminho de Deus. São Paulo: Loyola, 2009, p. 37.

${ }^{35}$ Para um melhor compreensão: GESCHÉ, A. O Cristo. São Paulo: Paulinas, 2003. (Deus para pensar; 2), pp. 201-219.

${ }^{36} \mathrm{Cf}$. GESCHÉ, A. A invenção cristã do corpo, p. 50.

${ }^{37}$ Cf, CARO, O.C.V. "Del Dios omnipotente a 'la humildad de Dios'. Uma reflexión sobre la 
que Deus dê espaço para que a criação exista. Este espaço é somente possível pela Kénose de Deus. ${ }^{38}$

Na Kénose, Deus adentra a história não com uma postura socorrista, de alguém superior que compartilha um pouco dos seus recursos. A encarnação é uma opção radical que faz com que o Deus Totalmente Outro decida esvaziar-se de sua própria glória, humilha-se, identifica-se com a dor e, opera plena e completamente a restauração e libertação do homem. Cria com isso um modelo de compreensão e conduta que afeta a igreja de modo visceral, fornece uma nova valoração para a vida e se impõe como ética para a humanidade, ainda que esta venha lhe negar a verdade, na Igreja tal posicionamento se faz imperativo.

Gesché ainda propõe:

Precisamente, em consonância com a descoberta que a fenomenologia fez do corpo como lugar das relações com o outro, nossa intuição teológica confirma que o corpo é verdadeiramente um lugar privilegiado de encontro com Deus. Afinal, a Encarnação não é, por assim dizer, o lugar ontológico da vontade de Deus de nos encontrar, não é afinal, um lugar único de relação com Deus? E se assim é, quais são as repercussões valiosas desse novo modo de pensar teológico do corpo sobre outras maneiras de considerar a realidade humana? ${ }^{39}$

A corporeidade acaba por tornar-se este espaço hermenêutico de Deus e seu amor. Lugar onde o ser humano encontra mais do que a si mesmo, encontra a Deus e consequentemente encontra o outro. Corpo, caminho para Deus, lugar de encontro, onde o corpo é tanto lugar em que o homem se chega a Deus e mais ainda, onde Deus encontra o homem. E nessa abertura fundamental, o ser humano também se abre aos outros.

\section{Conclusão}

Cristo assumindo o corpo cumpriu em si toda a dignidade com que o homem foi criado. Pensar o corpo a partir de Cristo e sua dignidade por certo é um grande desafio. A encarnação do Verbo dá novo significado à questão

evolución em perpectiva kenótica". In: RUBIO, A.G.; PORTELLA, J.A. (orgs.). Fé cristã e pensamento evolucionista. Aproximações teológico-pastorais a um tema desafiador, 2012, p. 116.

${ }_{38}$ MOLTMANN, J. "La Kénosis divina em la creación y consumación del mundo". In: POLKINGHORNE, J. (ed.). La obra del amo, p. 190, citado em CARO, O.C.V., op. cit. p. 116.

${ }^{39}$ SCOLAS, P. A invenção cristã do corpo, p. 14. 
e lugar do corpo nos sentidos humanos. A afirmação da dignidade humana pelo corpo, em contraposição a cada vez mais indignidade que é marca deste tempo, é ação fundamental. Numa sociedade que, por um lado, absolutiza o corpo, transformando-o em espetáculo, com valor mercadológico, com status de divindade. Por outro, o rebaixa, violenta de todas as formas possíveis, corpo-próprio, corpo do outro, corpo da criação, faz-se urgente tal atenção. A Constituição Pastoral é bastante otimista em relação à humanidade. Otimismo que não é alienação, mas compreensão de onde o ser humano está ancorado, na imagem de Deus com que foi criado e na redenção do Cristo.

Faz desafio para a Igreja hoje pensar tais questões, pensar a vida em toda a sua dinâmica e tenacidade. Ainda mais que não se compreende como agência que se interessa pela vida pós-morte, somente. A Constituição Pastoral propõe que a Igreja Viva atue dinamicamente também na vida que se faz, com anelo irrefreável de que o Próprio autor da vida a guiará.

\section{Referências bibliográficas}

COSTA, P. C. A determinação cristológica do ser humano. Atualidade Teologica 39 (2011), pp. 503-511.

CARO, O.C.V. "Del Dios omnipotente a 'la humildad de Dios'. Uma reflexión sobre la evolución em perpectiva kenótica". In: RUBIO, A.G.; PORTELLA, J.A. (orgs.). Fé cristã e pensamento evolucionista. Aproximações teológico-pastorais a um tema desafiador. São Paulo: Paulinas, 2012.

FAMERÉE, J. "O corpo, caminho de Deus. A problemática". In: GESCHÉ, A.; SCOLAS, P. (orgs.). O corpo, caminho de Deus. São Paulo: Loyola, 2009, pp. 13-34.

GESCHÉ, A. O Cristo. São Paulo: Paulinas, 2003. (Deus para pensar; 2)

GESCHÉ, A. "A invenção cristã do corpo". In: GESCHÉ, A.; SCOLAS, P. (orgs.). O corpo, caminho de Deus. São Paulo: Loyola, 2009, pp. 35-79.

JUNGES, J. R. Bioética. Hermenêutica e casuística. São Paulo: Loyola, 2006.

LADARIA, L. F. Introdução à antropologia teológica. São Paulo: Loyola, 2002.

LIBANIO, J.B. Concílio Vaticano II: em busca de uma primeira compreensão. São Paulo: Edições Loyola, 2005. 
LOPES, G. Gaudium et Spes: texto e comentário. São Paulo: Paulinas, 2011.

MOSER, A. "Corpo e sexualidade: do biológico ao virtual". Disponível em: $<$ http://www.antoniomoser.com/site/index.php?option=com_content\& view $=$ article \&id=187:o-corpo-e-sexualidade-do-biologico-ao-virtual\&cati $\mathrm{d}=34$ :artigos\&Itemid=41>. Acesso em 18 de Maio de 2015 .

REIJNEN, A.M. "O corpo, canteiro de obras da redenção". In: GESCHÉ, A.; SCOLAS, P. (orgs.). O corpo, caminho de Deus. São Paulo: Loyola, 2009, pp 203-220.

RENDERS, H. A. "Estudos de gênero e método teológico: corporeidade e androcentrismo como temas permanentes do quadrilátero wesleyano brasileiro". Revista Estudos de Religião 39 (2010), pp. 91-106. Disponível em: <https://www.metodista.br/revistas/revistas-ims/index. php/ER/article/view/2076/2343>. Acesso em 15 de Maio de 2015.

RUBIO, A. G. Unidade na pluralidade. 3. ed. São Paulo: Paulus, 2001.

RUBIO, A. G. (org.). O humano integrado. Abordagens de antropologia teológica. Petrópolis: Vozes, 2007.

RUBIO, A. G. Elementos de antropologia teológica. Salvação cristã: salvos de quê e para quê?. $4^{\text {a }}$ Ed. Petrópolis: Vozes, 2007.

SCOLAS, P. "O corpo, caminho de Deus, ou a invenção cristã do corpo". In: GESCHÉ, A.; SCOLAS, P (orgs.). O corpo, caminho de Deus. São Paulo: Loyola, 2009, pp. 7-11.

Jonathan Bahia Vieira

Mestrando em Teologia pela Pontifícia Universidade Católica

do Rio de Janeiro

Rio de Janeiro / RJ - Brasil

e-mail: jonathanbahia@yahoo.com.br

Recebido em: 21/05/15

Aprovado em: 25/06/15 